\title{
Batik Pattern Identification using GLCM and Artificial Neural Network Backpropagation
}

\author{
Ayu Ratna Juwita \\ Faculty of Technology and Computer Science \\ Buana Perjuangan University \\ Karawang, Indonesia \\ ayurj@ubpkarawang.ac.id
}

\author{
Achmad Solichin \\ Faculty of Information Technology \\ Budi Luhur University \\ Jakarta, Indonesia \\ achmad.solichin@budiluhur.ac.id
}

\begin{abstract}
Batik is a craft that has high artistic value and has become part of Indonesian culture. Preservation of batik must continue to be carried out so as not to be eroded by the times. One of the efforts to preserve batik is by digitizing batik patterns. With the diversity of batik patterns in Indonesia, digitizing motives is not only saved it in digital format but also how to retrieve and identify the batik patterns. In this study, we proposed a classification of Karawang batik pattern using backpropagation artificial neural networks and gray level cooccurrence matrix (GLCM) features. The step of the classification process begins with changing the image of batik from the color image to the grayscale image. Next, image segmentation is carried out to separate the batik pattern with its background using the Otsu method. Segmented images are extracted from GLCM features that are used as a feature in the classification process. Based on the results of testing using 50 test images, the accuracy value was $80 \%$, the precision value was $91 \%$, and the recall value was $83 \%$.
\end{abstract}

Keywords-Artificial Neural Network Backpropagation, Batik Pattern, Image Processing, Otsu Method, GLCM

\section{INTRODUCTION}

Batik is one of the traditional works of art that has been recognized as Indonesian cultural heritage by UNESCO. In Indonesia, Batik can be found in almost every region. Each region has its characteristics, especially regarding patterns and manufacturing processes. In the book entitled "Batik: Spirit of Indonesia," it is stated that in Indonesia there are more than 181 batik patterns [1]. However, the development of the batik industry in several regions makes the diversity of batik patterns continue to increase [2].

The diversity of batik patterns in Indonesia must continue to be preserved for future generations. One of the efforts to preserve batik is by digitizing batik patterns. With the diversity of batik patterns in Indonesia, digitizing patterns is not only digital storage but how to quickly retrieve and identify the batik patterns. In this research, we digitize and recognize the batik patterns were devoted to batik patterns in Karawang, West Java, Indonesia.

Several studies to recognize batik patterns have been carried out. In research by Kasim and Harjoko [3], batik was classified using the canny segmentation method, feature extraction of GLCM and RGB statistical color. In other studies, the method of Fuzzy Neural Network was used, and the extraction of wavelet features to detect the similarity of batik patterns [5]. Suciati et al. in [6] used three methods in the extraction process, using Color Co-occurrence Matrix (CCM) and Different Between pixels of Scan Pattern
(DBPSP) to extract textures of batik patterns, and the Color Histogram for K-Means (CHKM) for color feature extraction of batik patterns.

In this study, the GLCM feature is used because it has advantages over the Canny and Gabor features [2], [4]. While for classification used Backpropagation method, and for image segmentation phase using the Otsu method. Meanwhile, training data and test data were obtained from recording Karawang batik patterns, West Java, Indonesia. With this research, it is expected to help preserve Karawang Batik through the process of digitizing batik patterns.

\section{LITERATURE REVIEW}

\section{A. Image Processing}

An image can be defined as the function of the $(\mathrm{x}, \mathrm{y})$ sized $\mathrm{M}$ rows and $\mathrm{N}$ columns, where $\mathrm{x}$ and $\mathrm{y}$ are spatial coordinates and the amplitude $\mathrm{f}$ at the coordinate point $(\mathrm{x}, \mathrm{y})$ [5]. If the value of $x, y$, and the amplitude value $f$ is finite and discrete, then it can be said that the image is a digital image [6]. Grayscale image is a digital image that has only a channel value on each pixel. In other words the RED $=$ GREEN $=$ BLUE. The value is used to indicate the level of intensity. The colors are black, gray, and white. The gray level here is a color of gray with varying degrees from black to close to white [6]. To get grayscale image using the formula (1).

$$
\mathrm{I}(\mathrm{x}, \mathrm{y})=\alpha \cdot R+\beta \cdot G+\gamma \cdot B
$$

Segmentation is the process of dividing an image into the components of the region or object. The segmentation algorithm is generally based on one of the basic properties of the intensity value [7], namely:

1. Discontinuity: approach by dividing the image based on significant changes in the intensity value, such as the edge of the image.

2. Similarity: an approach by dividing the image into similar regions with the initial criteria given. Examples of this approach are thresholding, region growing and region splitting and merging.

The Otsu method is one of the segmentation approaches. It automatically calculates threshold values based on the input image. The approach used by the Otsu method is to conduct a discriminant analysis that determines a variable that can distinguish between two or more groups that arise naturally. The discrete analysis will maximize these variables in order to separate objects against the background [6]. 


\section{B. GLCM (Gray Level Co-Occurrence Matrix)}

GLCM (Gray Level Co-Occurrence Matrix) is a matrix constructed using a second level histogram. The cooccurrence matrix is an LxL-sized matrix, where $\mathrm{L}$ is the number of gray levels in the original image [6]. The matrix contains probability values of two pixels with grayscale intensity and gray level intensity, each separated by distance $\mathrm{d}$ and direction $\theta$. Thus, the probability value can be written as $P(i, j, d, \theta)$.

\section{Neural Network Backpropagation}

Backpropagation is a supervised learning algorithm and is commonly used by perceptrons with multiple layers to alter the weights connected to the neurons present in the hidden layer. Backpropagation algorithm uses output error to change the value of the weights in the backward direction. To get this error, forward propagation stage must be done first. At the time of advanced propagation, the neurons are activated by using sigmoid activation function [6] as seen at formula (2).

$$
f(x)=\frac{1}{1+e^{-x}}
$$

\section{SySTEM AND APPLICATION DESIGN}

In this research, method describes the modeling procedure and implements the method of artificial neural network backpropagation to classify the image of batik with gray level co-occurrence matrix can be seen in Figure 1.

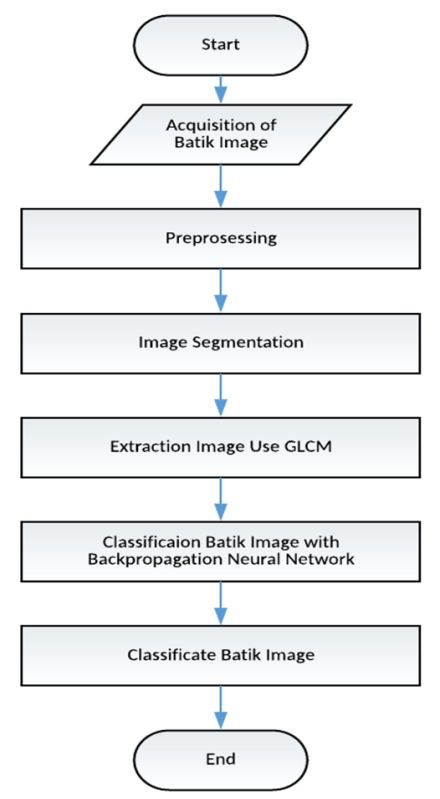

Fig. 1. The Proposed Method

Fig. 1 explains the problem solving with a computational approach to batik pattern classification

1. The acquisition of the Batik image.

Collecting the image of batik of some pattern of batik Karawang and every image of batik pattern is stored on file with image format $* . j p g$.

2. Preprocessing

The preprocessing process is done by taking samples of certain parts of the batik pattern. Next, it will be converted into grayscale image using formula (1). Figure 2 shows the original image and grayscale image.

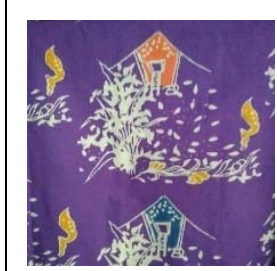

(a)

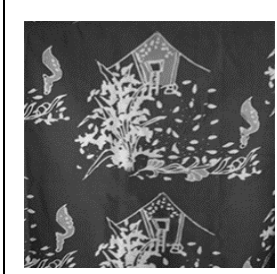

(b)
Fig. 2. Figure (a) original image and image (b) grayscale image

\section{Segmentation}

Image segmentation aims to get a specific object or a region of interest in the image that will be processed in the next stage. In this study, the segmentation of batik patterns was carried out using the Otsu method. The formulation of the Otsu method is calculated by (3). P(i) is the probability of intensity, $\mathrm{n}_{\mathrm{i}}$ is number of pixels with intensity $\mathrm{i}$, and $\mathrm{N}$ is number of all pixels.

$$
P(i)=\frac{n_{i}}{N}, p(i) \geq 0, \sum_{1}^{256} p(i)=1
$$

Based on the probability of every pixel, we compute the histogram into two classes (object and background). The weights in both classes are expressed by (4) and (5).

$$
\begin{aligned}
& w_{1}(t)=\sum_{i=t+1}^{t} p(i) \\
& w_{2}(t)=\sum_{i=t+1}^{L} p(i)=1-w_{1}(t)
\end{aligned}
$$

\section{Feature Extraction}

The extraction of GLCM features is done to get values that can represent batik patterns. In this study, we extract six features of GLCM, ie. Contrast, Energy, Homogeneity, Correlation, Standard Deviation, Entropy.

1. Contrast $=\sum_{a, b} P_{a, b}(a-b)^{2}$

2. Energy $=\sum_{a, b} P_{\emptyset, d}^{2}(a-b)$

3. Homogenities $=\sum_{a} \sum_{b} \frac{1}{1+(a-b)^{2}} P_{\emptyset, d}$

4. Correlation $=\frac{\sum_{a, b}\left[(a b) P_{\emptyset, d(a, b)-\mu_{x} \mu_{y}}\right.}{\sigma_{x} \sigma_{y}}$

\section{Standard Deviation}

$$
\left[\frac{1}{a b-1} \sum_{i=1}^{a} \sum_{j=1}^{b}\left(p_{i j-\mu_{c}}^{c}\right)^{2}\right]^{\frac{1}{2}}
$$

6. Enthropy

$$
=-\sum_{i} \sum_{j} N g(i, j) \log _{2} N_{g}(i, j)
$$


GLCM formation stage with direction $0^{\wedge} 0$ and distance $\mathrm{d}=1$ then determined the direction coordinates $(\mathrm{x}, \mathrm{y})$ that is (1.0). After the direction is determined then formed cooccurrence matrix by calculating the frequency of occurrence of pairs of gray pixel value pair at the distance and direction which have been determined.

5. Classification of Batik Pattern Image

To classify the pattern of batik we use the artificial neural network with backpropagation method to divide the image of batik into several classes.

\section{RESULT AND DISCUSSION}

In this research use some technique of digital image processing for identification of batik pattern. The model for identification of batik pattern in this study as Figure 3 .

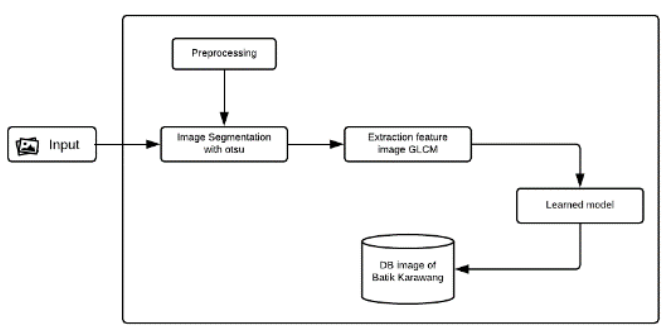

Fig. 3. The concept of training data identification of batik

The concept of image acquisition in the classification model consists of 3 processes, namely :

1. Input : Test image capture process

2. Process : the result of preprocessing, segmentation and extraction of images will be classified with the data sets present in the training data.

3. Output : Results Classification batik pattern Karawang.

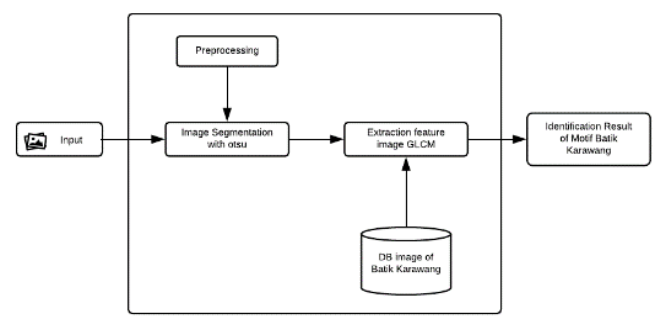

Fig. 4. The concept of batik classification

The concept of batik classification model consists of 3 processes, namely :

1. Input: Test image capture process

2. Process : the result of preprocessing, segmentation and extraction of images will be classified with the data sets present in the training data.

3. Output : Results Classification batik pattern Karawang.

The design of the system flow is a stage to design step by step process to be performed by the system to be created. The flow of batik classification system is as follows :

1. The system starts by selecting an existing image.
2. The second stage is to transform the image into a grayscale image.

3. Phase three segmentation using otsu.

4. The fourth stage of feature extraction value is Contrast, Energy, Homogeneity, Correlation, Entropy.

5. The fifth stage takes the results of training data from the database.

6. The sixth stage is classification with artificial neural network backpropagation.

a. image acquisition

Image acquisition is the stage of data retrieval. This stage starts with preparing the object image of batik images that will be used as input until the appearance of batik object image used. Image of batik image used 750x750pixel, with image format *.jpg. The program code for image acquisition is as follows :

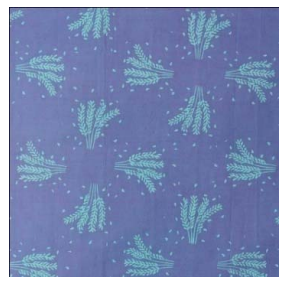

Fig. 5. Initial image input

In Figure 5 is the image of the input that has not been through the image processing, the image of the input is still a color image with the RGB format. Next on RGB image will be pre-processing so that segmentation and feature extract can produce correct feature identification.

b. pre-processing

After the image is acquired, the next step is the preprocessing stage, which in this step is done image quality improvement from the image insert that still raw data (raw data) into a quality image, thus increasing the likelihood of success in the stage of image processing in the next stage.

At the pre-processing stage, the image conversion process becomes the gray image and eliminates the noise in the image. As for the process is as follows:

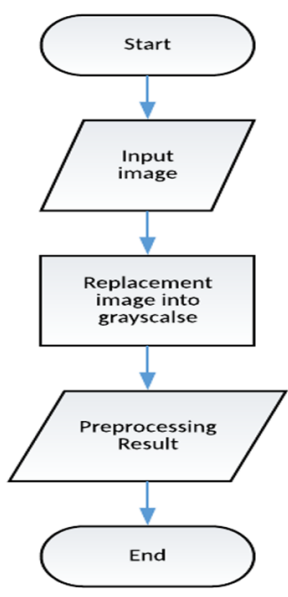

Fig. 6. Pre-processing process flow

After entering the original image will be converted into a grayscale image and will eliminate noise in the image. Here are the results of the pre-processing process. 


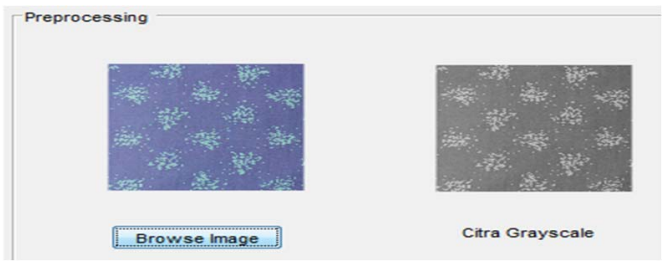

Fig. 7. pre-processing result

c. image segmentation

Image segmentation is intended to get a specific object or an area in the image for matching or identification making it easier to analyze. The result of pre-processing will be processed image segmentation using Otsu to detect batik pattern.

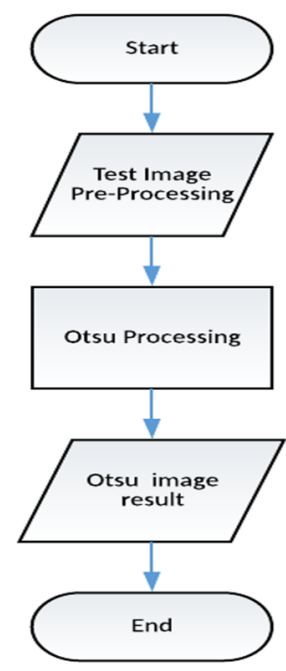

Fig. 8. flow process of segmentation

Indicates in the previous stage the image will be processed into the result of segmentation otsu as follows.
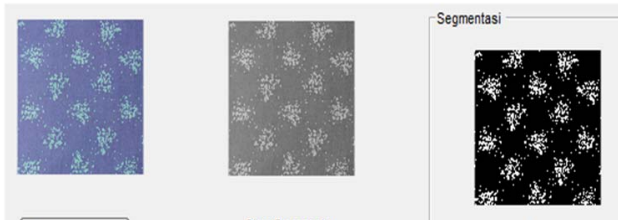

Browse image

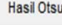

Fig. 9. Results of otsu segmentation process

\section{d. Feature extraction}

At the extract stage features a texture with Gray Level CoOccurrence Matrix (GLCM). GLCM texture feature extraction is performed to obtain values that can represent images. There are six extraction feature features used, namely entropy, contrast, homogeneity, correlation, energy, avg gray level which results will be done in the calculation of multiclass confusion matrix. So that will get the results for the identification of batik.

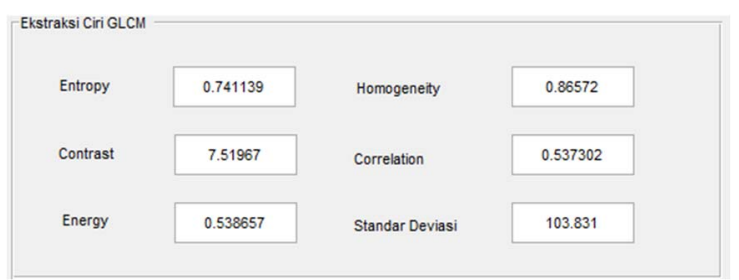

Fig. 10. The result of Gray Level Co-occurrence Matrix value

e. Classification of Backpropagation Neural Networks

At this stage is a supervised backpropagation learning stage. In the backpropagation network, each unit in the input layer is connected to each unit in the hidden layer. Each unit in the hidden layer is connected to each unit in the output layer. When the network output is not equal to the expected output then the output will be backward on the hidden layer forwarded to the unit on the input layer. The following process flow process of batik identification

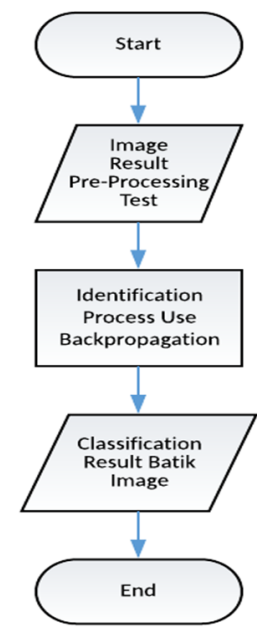

Fig. 11. Process flow classification

In the process of batik classification using backpropagation neural network that will bring the results of classification of batik image in accordance with the data input. For the backpropagation network architecture to be designed consists of 6 neurons in the input layer, 38 neurons in the hidden layer and 1 neuron in the output layer The number of neurons in the input layer is determined based on the number of extracted features. The number of neurons in the output layer is determined based on the target output value. Artificial neural network architecture designed in this study is as follows.

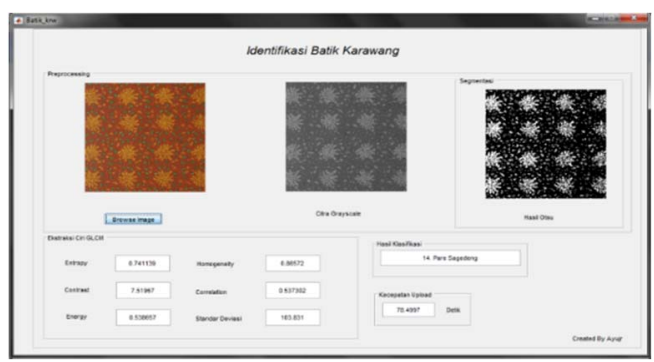

Fig. 12. The result of batik karawang classification

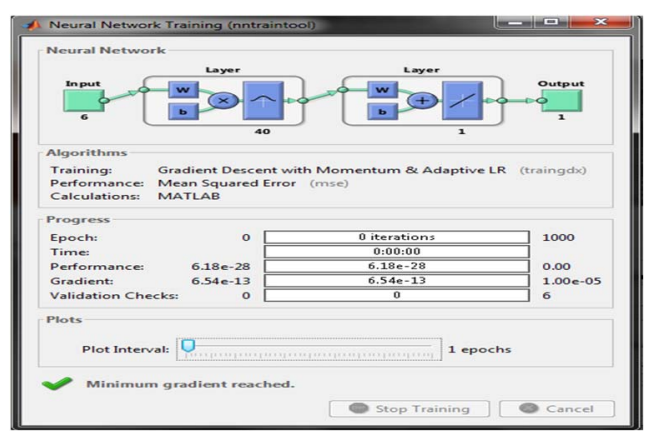


Fig. 13. Neural network backpropagation architecture results

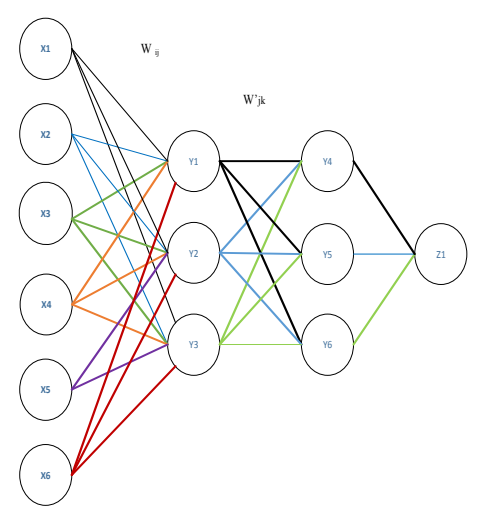

Fig. 14. The backpropagation architecture is HIDDE value 40

The explanation of artificial neural network architecture backpropagation in Figure IV - 145 are:

1. The input layer has six neurons, the hidden layer has 6 neurons, and the output layer has 1 neuron.

2. $\mathrm{x} 1$ through $\mathrm{x} 6$ are the neurons in the input layer, $\mathrm{y} 1$ to y6 are the neurons in the hidden layer, while the $\mathrm{z} 1$ neurons in the output layer.

3. $\mathrm{w}_{\mathrm{ij}}$ is the connection weight between the input layer and the hidden layer, while $w^{\prime} j \mathrm{k}$ is the connection weight between the hidden layer and the output layer.

The process of the backpropagation training phase is to set the error value to become smaller or by making the output value close to the target. After network training is completed, the final weight of the training process will be stored, where the final weights will be used during the testing phase. The initial process begins with the training data input stage into the network. In this study, there are 15 training data entered for each type of image of batik, so the overall data input for training data amounted to 50 data. In the input layer on the backpropagation consists of 6 features of the extraction.

\section{f. Testing}

Tests conducted on several types of batik image Karawang and not batik Karawang done as much as 50 images, with the following types of classification

TABLE I. TYPE OF ClASSIFICATION

\begin{tabular}{|l|l|}
\hline Pattern Type & Classification ID \\
\hline Unknown Pattern & 0 \\
\hline Aneka Padi & 1 \\
\hline Batang Padi & 2 \\
\hline Bulir Padi & 3 \\
\hline Ceplok Kapas & 4 \\
\hline Cigentis & 5 \\
\hline Citaruman & 6 \\
\hline Kembang Goyang & 7 \\
\hline Kombinasi Bunga Tarum & 8 \\
\hline Kombinasi Ceplok Sawah & 9 \\
\hline Kombinasi Pare Sagedeng & 10 \\
\hline Leuit & 11 \\
\hline Padi Cere Bulu & 12 \\
\hline
\end{tabular}

\begin{tabular}{|l|l|}
\hline Pattern Type & Classification ID \\
\hline Panen Raya & 13 \\
\hline Pare Sagedeng & 14 \\
\hline Empat Tangkai Padi & 15 \\
\hline
\end{tabular}

TABLE II. COMPARISON OF GLCM FEATURE VALUES

\begin{tabular}{|c|c|c|}
\hline No & Type of value GLCM & Result \\
\hline 1 & $\begin{array}{c}\text { Contrast, Energy, } \\
\text { Homogeneity, Correlation, } \\
\text { Entropy, Average Grey Level } \\
\text { (Mean), and standard } \\
\text { deviation. }\end{array}$ & $68 \%$ \\
\hline 2 & $\begin{array}{c}\text { Contrast, Energy, } \\
\text { Homogeneity, Correlation, } \\
\text { Entropy. }\end{array}$ & $65 \%$ \\
\hline 3 & $\begin{array}{l}\text { Energy, Homogeneity, } \\
\text { Correlation, Entropy. }\end{array}$ & $65 \%$ \\
\hline 4 & $\begin{array}{c}\text { Contrast, Energy, } \\
\text { Homogeneity, Correlation, } \\
\text { Entropy, Average Grey Level } \\
\text { (Mean), }\end{array}$ & $68 \%$ \\
\hline 5 & $\begin{array}{c}\text { Contrast, Energy, } \\
\text { Homogeneity, Correlation, } \\
\text { Entropy, dan standar } \\
\text { deviasi. }\end{array}$ & $80 \%$ \\
\hline
\end{tabular}

TABLE III. RESULTS OF THE CONFUSION MATRIX OF BATIK IMAGE

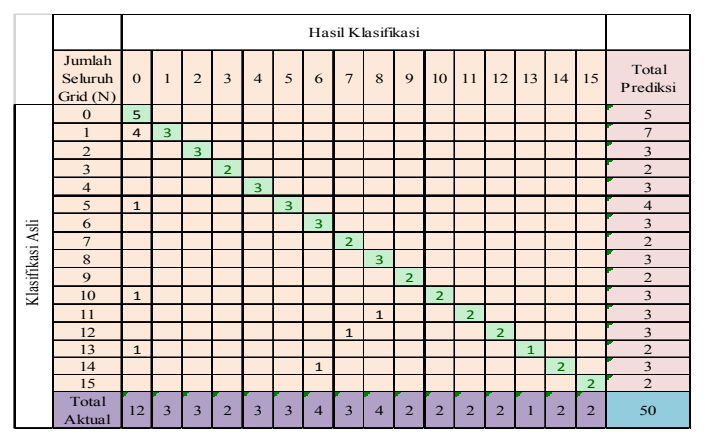

$$
\begin{array}{r}
T P(1)+T P(2)+T P(3)+T P(4) \\
\text { Accuracy }=\frac{N+T P(15)}{N} \\
=\frac{5+3+3+2+3+3+3+2+3+2}{+2+2+2+1+2+2} \\
=\frac{40}{50}=0,8
\end{array}
$$

Results from 50 classification experiments on batik image if presented at $80 \%$ accuracy value obtained. $91 \%$ precision and $83 \%$ recall results.

\section{CONCLUSION}

Based on the results of the research discussions that have been described, then this study has answered research questions, as follows: 
1. Karawang batik identification system model is done with the pre-processing stage to transform the original image into grayscale, then segmentation phase of the image using Otsu method for segmentation process, extraction of image features with GLCM method (Gray Level Cooccurrence Matrix) to detect the image of batik, feature extraction results are used as input to be classified using backpropagation neural network.

2. In the application of batik image classification model Karawang, this can classify with 50 batik image test, 40 images of batik Karawang, ten images of batik outside Karawang reach $80 \%$ accuracy, the result of the average value of precision reach $91 \%$ average recall reached $83 \%$.

\section{REFERENCES}

[1] D. Putra, Pengolahan Citra Digital. Yogyakarta: ANDI, 2010.

[2] A. A. Kasim and A. Harjoko, "Klasifikasi Citra Batik Menggunakan Jaringan Syaraf Tiruan Berdasarkan Gray Level Co- Occurrence Matrices ( GLCM )," Semin. Nas. Apl. Teknol. Inf. Yogyakarta, 21 Juni 2014, pp. 7-13, 2014.

[3] A. H. Rangkuti, "KLASIFIKASI PATTERN BATIK BERBASIS KEMIRIPAN CIRI DENGAN WAVELET TRANSFORM DAN FUZZY NEURAL NETWORK," no. 9, pp. 361-372.

[4] N. Suciati, W. A. Pratomo, and D. Purwitasari, "Batik Pattern Classification using Color-Texture-Based Feature Extraction and Backpropagation Neural Network," 2014.

[5] A. Kadir and A. Susanto, Teori dan Aplikasi Pengolahan Citra. Yogyakarta: Andi, 2013.

[6] S. Kusumadewi, Arificial Intelligence (Teknik dan Aplikasinya). Yogyakarta: Graha Ilmu, 2003. 